\title{
Status Quo of Research and Practice of Emerging Engineering Education in China
}

\author{
Xiaojun Ma, Chunjiang Li*, Defu Shao \\ School of Mechanical Engineering \\ Jiamusi University \\ Jiamusi, Heilongjiang 154007, China \\ *The Corresponding author
}

\begin{abstract}
This paper expounds the development of the trilogy of emerging engineering education construction of "Fudan Consensus", “Tianjin University Action" and "Beijing Guide”, analyzes the status quo of research and practice of emerging engineering education in China, and puts forward the key technology for the cultivation of the innovation ability of emerging engineering talents in local colleges and universities, with a view to providing reference for the further research of emerging engineering education.
\end{abstract}

Keywords - emerging engineering education; trilogy; research status; innovation ability

\section{INTRODUCTION}

The emerging engineering education is the hot topic and research frontier in the field of higher engineering education. "Fudan Consensus", "Tianjin University Action" and "Beijing Guide" constitute the "trilogy" of emerging engineering education construction. On February 20th, 2017, The Ministry of Education issued the "Notice of the Research and Practice of Emerging Engineering Education in the Department of Higher Education of the Ministry of Education", and launched the "Emerging Engineering Education Research and Practice" project. As of December 2nd, 2017, CNKI had indexed 147 articles (including newspapers) about research and practice on emerging engineering education, covering construction route, form and connotation of the education, innovative training mode of creative talents, foreign experience reference and enlightenment, innovation and entrepreneurship education, reform and practice, curriculum reform, etc. and emerging engineering education construction path and method and so on. The content revolves around the definition of the core concepts of emerging engineering education: new idea, new structure, new model, new quality and new system, hence forming the new normal of higher engineering education.

\section{EMERGING ENGINEERING EDUCATION TRILOGY}

\section{A. Fudan Consensus}

On February 18th, 2017, the seminar on the development strategy of higher engineering education was held in Fudan University. More than 30 colleges and universities from all over the country participated in the conference. The conference emphasized that the reform and development of higher

Funded Project: Key Entrustment Project of Higher Education Teaching Reform Research in Heilongjiang Province (SJGZ20180063) engineering education in China was standing at a new historical point, and analyzed that the world's higher engineering education was facing new opportunities and challenges. Therefore, colleges and universities in China must accelerate developing emerging engineering education. Engineering universities, engineering comprehensive universities and local universities should give full play to their role with the support of the government and society, learn from international experience. Initiate and implement the project of "Emerging Engineering Education Research and Practice”.

\section{B. Tianjin University Action}

On April 8th, 2017, the seminar on the construction of emerging engineering education was held in Tianjin University. More than 60 colleges and universities from all over the country attended the conference. The theme of the conference centered on exploring and establishing a new paradigm for engineering development. On the conference, studies were carried out on building specialty with industry needs to build a new structure for engineering majors; changing the content with technological development to update the engineering talent knowledge system; taking students as the center to innovate methods and means of the engineering education; pushing the reform of the school main body to explore the independent development and self-incentive mechanism of emerging engineering education; creating conditions with domestic and foreign resources to build an open and integrated new ecology of engineering education; focusing on international frontier standards to enhance the international competitiveness of engineering education.

\section{Beijing Guide}

On June 9th, 2017, the emerging engineering education research and practice expert group were established and the first working meeting was held in Beijing. More than 30 colleges and universities from all over the country participated in the meeting, in which the Guidelines for Emerging Engineering Education Research and Practice was deliberated and approved. The conference clarifies the objectives of emerging engineering education construction, strengthens the concept of engineering education, optimizes the structure of discipline and specialty, leads the development of technology and industry in the future, perfects multi-subject collaborative education, establishes multi-level and multi-field schoolenterprise alliance, builds a practice platform for regional and 
shared talents training, explores multi-disciplinary crossintegration, and consolidates innovation and entrepreneurship ability of engineering talents and explores the informationbased teaching reform of engineering education. In the conference, much of the attention was on classified development and that excellent university should play the main role of innovation, synthesize new technologies and industries by combining colleges and universities, and local universities should support with regional development goals. We should form some results for demonstration, build a number of new high-level science and engineering universities and colleges of industrialization, and create emerging engineering specialties, new courses, new platforms and new achievements.

\section{ANALYSIS OF THE STATUS QUO OF DOMESTIC EMERGING ENGINEERING EDUCATION RESEARCH}

$\mathrm{Hu}$ Bo et al. (2017) reached a consensus to accelerate the construction of emerging engineering education, promote the reform and innovation of engineering education and in Fudan at the Symposium on the Development Strategy of Engineering Education in Comprehensive Universities. Zhong Denghua (2017) studied the connotation and characteristics of the construction of emerging engineering education. The basic task of it is to cultivate diversified and innovative engineering and technical personnel, highlighting the characteristics of interdisciplinary integration. Lin Jian (2017) proposed that "emerging" refers to new, brand-new and new-born with leading, innovative, cross-integration and some other characteristics. Wu Aihua (2017) proposed to speed up the development and construction of emerging engineering education, to actively adapt to and lead the new economy. $\mathrm{He}$ cited the steps taken by Tianjin University to promote the demonstrative School of Microelectronics and Software, to set up industry-related majors, and measures to cultivate innovative and entrepreneurship engineering and technical talents through diversification and individualization, to address the shortage of talents in key areas. Chen Hui et al. (2017), taking Sun Yat-sen University as an example, put forward the path for comprehensive universities to develop emerging engineering education, that is, utilize the advantages of multidisciplinary education and location. Lu Guodong (2017) brought forward five "two" development subjects for the construction of emerging engineering education: teachers and students, innovation and change, online and offline space, two platforms inside and outside the school, and two guarantees for professional certification and recognition.

Zhang Fengbao (2017) put forward the path and method of emerging engineering education construction, and proposed to integrate ideological and political education with professional education, strengthen the concept of engineering education, make perfect the structure of emerging engineering education specialty, innovate the talent training system of entrepreneurship education, and train emerging engineering education talents with craftsman spirit. Li Deyi et al. (2017) put forward the idea of establishing an artificial intelligence institute to explore the reform concept of engineering education based on the integration of knowledge and practice and the application of knowledge. Zhang Daliang (2017) raised the idea of changing according to the times; returning to the original and innovating; developing emerging engineering education. Lin Jian (2017) proposed the concept of a new discipline as an upgraded version of the Education and Training Plan for Excellent Engineers. Zhou Jianfeng et al. (2017) came up with the construction measures of multi-level, modular and integrated innovation of practical teaching system. Shao Defu et al. (2017) studied the training mode of innovation and entrepreneurship ability to emerge engineering education talents in local colleges and universities, constructed the curriculum system of innovation and entrepreneurship ability training of engineering talents, as well as the implementation path and method. Ye Hong et al. (2017) put forward to evaluating the training of innovative talents and students' abilities in emerging engineering education by using developmental evaluation. Li Peigen (2017) advanced the new concept of engineering and some "new qualities" that engineering talents should possess facing the future. Shi Xiaoqiu et al. (2017) built an emerging engineering education system of local universities which is integrated, open and adaptive. Gong Xiaojia (2017) proposed the model of studentcentered and school-enterprise joint training. Yang Yigang (2017), from the perspective of economics, put forward that emerging engineering education talents should have the ability of economic decision-making. Shen Jianxin et al. (2017) put forward the idea of multi-cooperation to realize school-based curriculum development. Li Qiquan (2017) discussed the engineering culture education in the construction of "new subject”.

\section{EXPLORATION OF THE CULTIVATION OF EMERGING ENGINEERING EDUCATION TALENTS' INNOVATIVE ABILITY}

Under the background of emerging engineering education construction, the reform and development of engineering education in local colleges and universities are facing opportunities and challenges. Centering on strengthening moral education and cultivating people, we should make clear the orientation of school running, layout discipline specialties, break down discipline barriers, construct school-local, schoolenterprises and school-school communities, and promote the reform of engineering education and teaching. We should also establish the training path of innovative engineering talents, form the training mode of innovative and entrepreneurship ability of emerging engineering education talents with innovative engineering education ideas, create new ideas and models, new structure, new system and new quality of engineering education, hence playing a supporting role for regional economic development and industrial upgrading.

Focusing on the basic requirement of strengthening moral education and cultivating people, we should advance the concept of innovative engineering education. The craftsman spirit of "striving for perfection and excellence" should be integrated into the professional education of emerging engineering education in an all-round and profound way. Emerging engineering education should be built as the main line, highlighting the characteristics of innovation and entrepreneurship education in local comprehensive universities and relying on platforms. The new entrepreneurship training model guided by the concept of innovative engineering education in all directions should be practiced and popularized. 
With innovation and entrepreneurship education as the core, we should constantly improve the innovation and entrepreneurship training for emerging engineering education talents. Firstly, we should improve the system and mechanism, stimulate students' creativity, excavate all kinds of innovative and entrepreneurship education resources with scientific toplevel design, and improve the effect of the education by a complete system. Secondly, we should promote multiple synergies, ensure students' innovation, and deeply integrate the supply of pre-eminent talents with production and learning, so as to enhance the students' innovative practical ability through deep cooperation between schools and local, enterprises and schools. Thirdly, we should create an environment to incubate students' entrepreneurship, and build innovation and entrepreneurship platforms such as entrepreneurship incubation base, science and technology entrepreneurship practice base and maker space. We should promote the deep integration of information technology and engineering education, innovate engineering education methods and improve the quality of personnel training.

\section{A. Integrating emerging engineering education concepts into professional education}

Major national strategies and needs are the important sources where engineering education reform and innovation begin. In order to support the transformation and upgrading of service industry and the transformation of economic development momentum and adapt to the new economy characterized by "new technologies, new products, new formats and new modes", it is urgent to deepen the reform of higher engineering education, conscientiously implement the higher education in personnel training, scientific research, social services, cultural heritage and innovation, and international exchanges and further strengthen the cooperation to undertake the historical mission of the great rejuvenation of the Chinese nation. The new needs of national strategic development require us to carry out higher education reform, and the construction of a scientific and rational curriculum system for engineering majors represents an important part of higher education reform. At present, the key to the China's manufacturing industry is to train high-quality skilled workers and emerging engineering education and technical personnel to meet the requirements of the development of the industry. However, today, although the graduates in colleges and universities are in a large number, they cannot meet the demand for talents under the new economic development situation. How to train high-quality and sustainable high-end technical talents stands for an urgent task for colleges and universities.

Modern teaching view holds that the aim of curriculum system teaching is to promote the development of human beings and to boost the comprehensive and sustainable development of all students. Correspondingly, learning is social, and learning is a process of social negotiation of knowledge. Through the new education mode, students are able to master modern science and culture and internalize it into innovation ability. Therefore, it is the intrinsic blending of seeking the truth, creating meaning and constructing spiritual world between subjects. In the course of building the curriculum system, we should break down the barriers between traditional disciplines, reform the curriculum system, pay attention to practicability and rationality, and construct new professional models such as "micro-specialty", like refining certain core professional courses and establishing curriculum teaching modules that integrate different knowledge; encouraging students of other disciplines or majors to take minor courses, which can not only enable most students to learn the specialized courses well, but also form a crossdisciplinary foundation and create a compound talent training. Furthermore, guided by the real problems and proceeding from the system of engineering problems, students can absorb the world's leading disciplines more quickly, directly and effectively, and cultivate students' various thinking modes and innovative thinking and analytical abilities.

\section{B. Optimization of talent training mode of emerging engineering education}

Against the backdrop of training outstanding engineers, this paper puts forward a systematic talent training model and puts it into practice, which cultivates "T-type" talents with solid theoretical basis and expertise in a certain field. In the concept of personnel training, we should base on theoretical knowledge, focus on project training, and center on cultivating students' practical ability and innovation and entrepreneurship. We should focus on the organic integration of cutting-edge technology, innovate teaching technology, focus on the cultivation of innovative thinking, integrate traditional teaching methods with new educational technologies such as virtual simulation technology, micro-course, MOOC course, etc., so as to form a double-helix teaching system with the combination of virtuality and reality, which fully integrates theoretical teaching and practical teaching and supports each other.

\section{Establishing a maker space to build an innovative and entrepreneurial education system}

In view of the new challenges of makers and entrepreneurship education, this paper proposes new training mode of applied talents based on engineering design thinking, and maker space and innovative courses are offered to form a relatively complete innovative and entrepreneurial education system. It cultivates students' innovative consciousness and entrepreneurship. In addition, it relies on students' extracurricular activities, the guidance of professional teachers and the campus atmosphere to create "three platforms" and leads the construction of the organizational system through the participation of the schools and colleges in top-level design, the integration of the whole process into the teaching link and high-end competitions, hence achieving "three effects" of students' professional assistance, the basic carrier of innovative education and self-improvement and self-confidence training education of students.

\section{Deepening the integration of production and education, and building a multi-level and multi-platform practical teaching system}

Agricultural electrification is a comprehensive subject with strong practicality. On the basis of theoretical teaching, practical teaching can enable agricultural electrification majors, 
in the construction of practical teaching system, emphasize the enterprise and industry joint training of talents through schoolenterprise cooperation, school-level cooperation and international cooperation. It focuses on the training of "doublecertificated" teachers, promotes "dual guidance” and "dual tutor system" and attaches importance to the construction of practical teaching bases both inside and outside schools to build a multi-level and multi-platform practical teaching system.

\section{REFERENCES}

[1] Guide for Emerging Engineering Education Construction (Beijing Guide) [J]. Research in Higher Education of Engineering, 2017, (04):20-21.

[2] Lin Jian. Emerging Engineering Construction Leading Higher Education Reform [J]. China Higher Education, 2017, (Z2):40-43.

[3] Zhang Fengbao. On the Path and Method of Emerging Engineering Education Construction -- Exploration and Practice of Tianjin University [J]. China University Teaching, 2017, (07):8-12.
[4] Zhong Denghua. Connotations and Actions for Establishing the Emerging Engineering Education[J]. Research in Higher Education of Engineering, 2017, (03):1-6.

[5] Lu Guodong. Five Breakthroughs and Preliminary Exploration in the Construction of Emerging Engineering Education[J]. China University Teaching, 2017, (05):38-41.

[6] Action Route of Emerging Engineering Education Construction (Tianjin University Action) [J/OL]. Research in Higher Education of Engineering, 2017, (02):24-25(2017-04-21). http://kns.cnki.net/kcms/detail/42.1026.G4.20170421.1739.010.html.

[7] Hu Bo, Feng Hui, Han Weili, Xu Lei. Accelerating the Establishment of New Engineering and Technical Disciplines and Promoting the Innovation in Engineering Education: A Review of the Symposium on the Strategy of Developing Higher Engineering Education[J]. Fudan Education Forum, 2017, 15(02):20-27+2.

[8] Fudan Consensus on Emerging Engineering Education Construction [J]. Fudan Education Forum, 2017, 15(02):27-28.

[9] Lin Jian. The Construction of China's New Engineering Discipline for the Future[J]. Research On Education Tsinghua University, 2017, 38(02):26-35.

[10] Wu Aihua, Hou Yongfeng, Yang Qiubo, Hao Jie. Accelerating Development and Construction of Emerging Engineering, Taking Initiative to Adapt to and Lead the New Economy[J]. Research in Higher Education of Engineering, 2017, (01):1-9. 